Bangl. J. Vet. Med. (2006). 4 (1): 07-12

\title{
AVIAN SALMONELLA INFECTION: ISOLATION AND IDENTIFICATION OF ORGANISMS AND HISTOPATHOLOGICAL STUDY
}

\author{
M. S. Hossain, E. H. Chowdhury, M. M. Islam, M. G. Haider and M. M. Hossain*
}

Department of Pathology, Faculty of Veterinary Science, Bangladesh Agricultural University, Mymensingh 2202, Bangladesh

*Corresponding author’s e-mail address: mokbul@royalten.net.bd ; mmhossain04@yahoo.com.au

\begin{abstract}
The Present study was performed in the Department of Pathology, BAU, Mymensingh during the period from January to December 2004. The study was conducted to determine the occurrence and pathology of pullorum disease, fowl typhoid and salmonellosis (paratyphoid infection) in dead chickens at necropsy in Mymensingh district of Bangladesh. A total of 70 samples (liver, ovary and intestine) were collected for isolation of bacteria in different media, and identification was performed based on the staining, cultural and biochemical properties of Salmonella spp. Routine histopathological method was used for the detection of tissue level alterations in Salmonella infected cases. Grossly, in all the infected cases the liver was enlarged and congested and in few cases, liver discoloration with focal necrosis. Old raised hemorrhages in the caecal tonsil and congested deformed ova were other important findings. There was catarrhal inflammation in the intestine. Microscopically, the section of livers showed congestion, hemorrhages, focal necrosis with infiltration of mononuclear cells. The pulmonary lesions consisted of sero-fibrinous exudation with mononuclear cell infiltration. The intestinal mucosa exhibited congestion, hemorrhages and infiltration of plasma cells, heterophils and macrophages. . Out of 70 samples, 8 isolates were identified as Salmonella (11.42 \%). Of them, five isolates were identified as Salmonella gallinarum, causative agent of fowl typhoid, one isolate was characterized as Salmonella pullorum, causative agent of pullorum disease and other two motile salmonella were identified as paratyphoid infection.
\end{abstract}

Keywords: Fowl typhoid, pullorum disease, paratyphoid, histopathology, isolation, identification

\section{INTRODUCTION}

One of the constraints in the poultry farms in Bangladesh is the outbreak of infectious diseases. Salmonella infection is one of the most important bacterial diseases in poultry causing heavy economic loss through mortality and reduced production (Haider et al., 2004; Talha et al., 2001). Avian salmonella infection may occur in poultry either acute or chronic form by one or more member of genus Salmonella, under the family Enterobacteriaceae (Hofstad et al., 1992). There are mainly two types of non motile avian Salmonella sp. namely Salmonella gallinarum and Salmonella pullorum that cause fowl typhoid and pullorum disease, respectively. Besides, motile Salmonellae (paratyphoid group) infection cause salmonellosis in chickens and have zoonotic significance. Prevention of salmonella infection is important for the profitable expansion of poultry industry in Bangladesh. Effective preventive and control measures cannot be undertaken unless status of the diseases and pathology are known. Therefore, the present study was undertaken to determine the incidence and pathology of fowl typhoid, pullorum disease and salmonellosis (paratyphoid infection) in dead chickens that had been submitted for the necropsy at the Department of Pathology, Bangladesh Agricultural University, Mymensingh.

\section{MATERIALS AND METHODS}

\section{Samples}

A total of 70 samples (intestine, ovary and liver) were collected at necropsy of chickens for bacteriological and pathological study in the Department of Pathology during the period of January to December 2004. For bacteriological study the cotton swabs were kept into the test tubes containing tetrathionate broth (TTB) which inhibits the growth of all bacteria except salmonella and for the pathological study the collected tissue samples were fixed in $10 \%$ neutral buffer formalin. 


\section{Used media and biochemical reagents}

Tetrathionate broth (TTB), Nutrient agar, Triple sugar iron (TSI) agar, MacConkey (MC) agar, Salmonella Shigella (SS) agar, Nutrient broth (NB), Triple Sugar Iron (TSI) agar, slant Methyl-Red solution, Bacterial Peptonea , Bacterial Peptone and MR-VP Medium were used.

\section{Isolation and identification of the organisms}

Test tubes containing samples were incubated for 24 hours at $37^{\circ} \mathrm{C}$ in Tetrathionate broth (TTB). From the TTB, subcultures were also made on nutrient agar, MacConkey agar, TSI agar and S-S agar, and incubated at $37^{0} \mathrm{C}$ for over night. The identification of the organisms was performed by the tests as described by Merchant and Packer, 1967; Cowan, 1974; Cheesbrough, 1985; Freeman 1995; and Brooks et al., 2002. On the basis of colony and staining characters, and biochemical tests the organisms were isolated and identified.

\section{Morphological characterization by Gram staining method}

The representative Salmonella colonies were characterized microscopically using Gram's stain according to the method described by Merchant and Packer, (1967).

\section{Identification of isolated Salmonella by using specific biochemical tests}

For this study carbohydrate fermentation tests, catalase test, TSI slant reaction, MR-VP reaction, indole reaction and dulcitol fermentation test were selected for identification of Salmonella suspected colonies. All of the isolates from different sources were tested for the detection of Salmonella spp according to the methods given in the OIE Manual (1996).

\section{Carbohydrate fermentation test}

The carbohydrate fermentation test was performed by inoculating a loop full of nutrient broth culture of the organisms into the tubes containing different sugar media (five basic sugars such as dextrose, sucrose, lactose, maltose, mannitol) and incubated for 24 hours at $37^{\circ} \mathrm{C}$. Acid production was indicated by the colour change of the medium reddish to yellow and the gas production was noted by the appearance of gas bubbles in the inverted Durham's' tube. Triple sugar iron agar (TSI) was used to detect the lactose fermenters, saccharose and dextrose fermenters. The medium also helped to determine the ability of the organisms to produce $\mathrm{H}_{2} \mathrm{~S}$. The organisms under study were heavily seeded with a platinum needle over the surface of the slants and stabbed into the butt of the tubes containing TSI agar. After an incubation of 24 hours at $37^{\circ} \mathrm{C}$ the tubes were examined for all changes in the slant or in the butt or in both places. Pinkish slant and yellow butt was recorded as the positive reaction.

\section{Methyl red test}

The test was performed by inoculating a colony of the test organism in $0.5 \mathrm{ml}$ sterile glucose phosphate broth (as used in the V-P test). After overnight incubation at $37^{\circ} \mathrm{C}$, a drop of methyl red solution was added. A positive methyl red test was shown by the appearance of a bright red color, indication of acidity. A yellow or orange color was treated as negative.

\section{Voges-Proskauer (V-P) test}

Two $\mathrm{ml}$ of sterile glucose phosphate peptone water was inoculated with the $5 \mathrm{ml}$ of test organisms. It was incubated at $37^{\circ} \mathrm{C}$ for 48 hours. A very small amount (knifepoint) of creatine was added and mixed. Three (3) ml of sodium hydroxide reagent was added and mixed by shaking. The bottle cap was removed and left for an hour at room temperature. It was observed closely for the slow development of a pink-red color for positive reactions.

\section{Indole test}

Two $\mathrm{ml}$ of peptone water was inoculated with $5 \mathrm{ml}$ of bacterial culture and incubated for 48 hours. Half (0.5) ml Kovac's reagent was added, shaked throughly and examined after 1 minute. A red color layer indicated indole positive. No red color development indicated negative.

\section{Dulcitol fermentation test}

This test was performed as like as carbohydrate fermentation test as described earlier. 


\section{Motility test}

The motility test was performed according to the method described by Cowan (1974) to differentiate motile bacteria from the non-motile one. Before performing the test, a pure culture of the organism was allowed to grow in nutrient broth. One drop of cultured broth was placed on the cover-slip and was placed inversely over the concave depression of the hanging drop slide to make hanging drop preparation. Vaseline was used around the concave depression of the hanging drop slide for better attachment of the cover-slip to prevent air current and evaporation of the fluid. The hanging drop slide was then examined carefully under 100-power objective of a compound microscope using immersion oil. The motile and non-motile organisms were identified by observing motility in contrasting with to and fro movement of bacteria.

\section{Maintenance of stock culture}

During the experiment it was necessary to preserve the isolated organisms for longer periods. For this purpose the organisms from pure culture were inoculated into the tubes containing TSI slants and nutrient agar slant and incubated at $37^{\circ} \mathrm{C}$ for 24 hours. After the growth of organisms the tubes were sealed with paraffin wax and kept in the refrigerator at $4^{0} \mathrm{C}$ for further studies.

\section{Gross Pathology}

The postmortem examination in all the cases was performed for the dead birds. At necropsy, gross tissue changes were recorded carefully, and representative tissue samples containing lesions were fixed in $10 \%$ neutral buffered formalin for histopathological studies.

\section{Histopathology}

The tissues were trimmed, washed, processed in ascending grades of alcohol, cleared in chloroform, embedded in paraffin, sectioned using a microtome and stained as per standard procedure (Luna, 1968).

\section{Photomicrography}

Photomicrography was taken at the Department of Pathology using photomicrographic camera (Olympus PMC 35 Model).

\section{RESULTS AND DISCUSSION}

\section{Bacteriological study}

The prevalence of salmonella infection in liver, ovary and intestinal swabs of dead poultry was $11.42 \%$. The findings revealed that prevalence was higher in liver and ovarian sample than intestinal samples. Details can be seen in Table 1.

Table 1. Prevalence of Salmonella infection in the dead birds submitted at necropsy

\begin{tabular}{|lllll|}
\hline Location of sample & $\begin{array}{l}\text { Samples tested } \\
(\mathrm{n}=70)\end{array}$ & $\begin{array}{l}\text { Occurrence } \\
\text { of isolates }\end{array}$ & $\begin{array}{l}\text { Total number } \\
\text { of isolates }\end{array}$ & $\begin{array}{l}\text { Overall prevalence } \\
\text { among tested cases (\%) }\end{array}$ \\
\hline Liver & 20 & 03 & 08 & 11.42 \\
Ovary & 30 & 04 & & \\
Intestine & 20 & 01 & & \\
\hline
\end{tabular}

$\mathrm{n}=$ Total samples cultured for isolation of Salmonellae

Among the 8 isolates, 3 samples were isolated from liver $(n=20), 4$ from ovary $(n=30)$ and 1 from the intestine $(\mathrm{n}=20)$. These findings revealed that liver and ovary are the main target for the isolation of Salmonella, which is in close agreement with Sujatha et al. (2003).

In the present study, specific biochemical media were used for the detection of Salmonella. All of the isolates fermented dextrose, mannitol and xylose but did not ferment lactose and sucrose and all of the isolates were indole negative, methyl red positive and VP negative which are special biochemical characters for Salmonella spp. (table 2) that previously suggested by a number of scientists (Christensen et al., 1993; Robinson et al., 2000). 
Table 2. Biochemical activities of different isolates from liver, ovary and intestine

\begin{tabular}{|llllllllllll|}
\hline \multicolumn{1}{|c}{ Carbohydrate fermentation test } & Indole & MR & VP test & $\begin{array}{l}\text { Motility } \\
\text { test }\end{array}$ & Dulcitol & $\begin{array}{l}\text { Name of isolated } \\
\text { bacteria }\end{array}$ \\
\cline { 1 - 5 } D & Xy & S & L & Mn & & & & & & \\
\hline AG & AG & - & - & AG & - & + & - & - & AG & S. gallinarum \\
AG & AG & - & - & AG & - & + & - & - & - & S. pullorum \\
AG & AG & - & - & AG & - & + & - & + & AG & Other motile Salmonellae \\
\hline
\end{tabular}

$\mathrm{D}=$ Dextrose, $\mathrm{Xy}=$ Xylose, $\mathrm{S}=$ Sucrose, $\mathrm{L}=$ Lactose, $\mathrm{Mn}=$ Mannitol, MR = Methyl Red, $\mathrm{VP}=$ Voges-proskauer test, $\mathrm{AG}=$ Acid and Gas, + = Positive and $-=$ Negative.

In this study, the colony characters of Salmonella, the production of hydrogen sulfide gas with black color colonies on TSI agar (Fig. 1) was corresponded with the findings of others (Old, 1990; Shrama and Katock, 1996). In Gram's staining, the morphology of the isolated bacteria was small rod shape, gram negative, single or paired in arrangement (Fig. 2) which also corresponded with morphological characters of Salmonella as described by several authors (Freeman, 1995 and Jones et al., 1997).

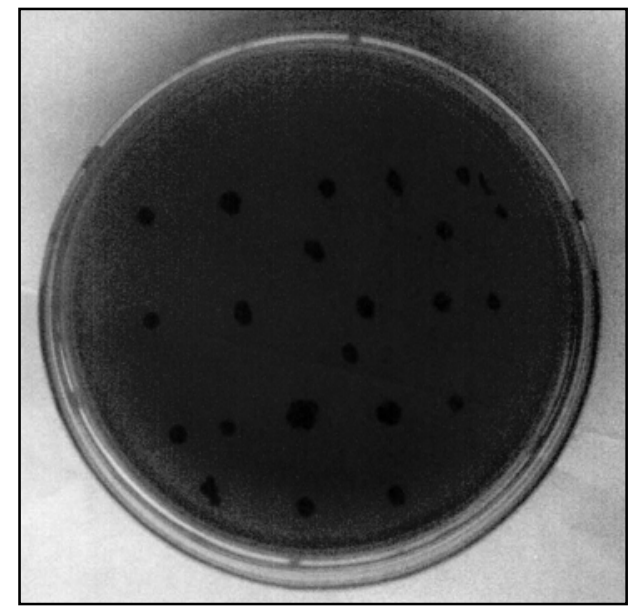

Fig. 1. Salmonella spp. produced black colonies on TSI medium.

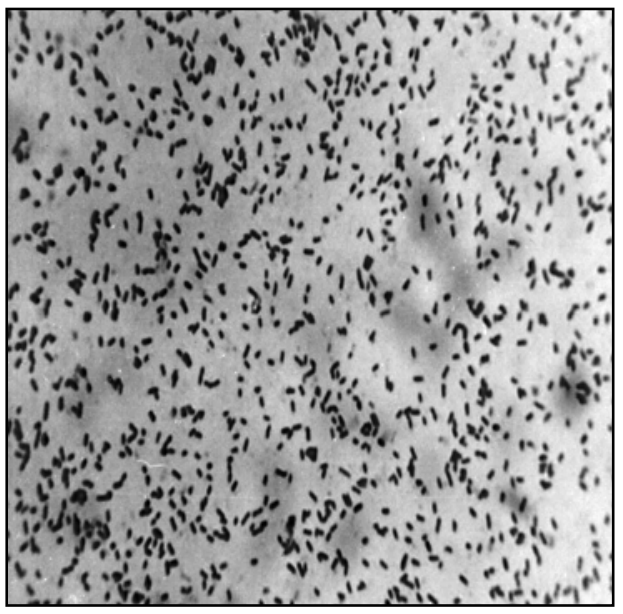

Figure 2. Salmonella spp. as gram negative, pink colour, small rod shape organisms, arranged in single or paired (Modified Gram stain, X 830).

In the present study six of the isolates were non-motile and two were motile. Motility test was fundamental basis for the identification of motile and non-motile Salmonella organisms (Buxton and Fraser, 1977; Freeman, 1995). Non-motile organisms were considered to be either $S$. pullorum or S. gallinarum. The motile organisms were considered as others species of Salmonella under Paratyphoid group (Pomeroy and Nagaraja, 1991; Christensen et al., 1993 and OIE manual, 1996).

The ability or inability of Salmonella to ferment different carbohydrates was used as fundamental basis for their isolation but species identification was difficult (Freeman, 1995). In the present study five out of six isolated nonmotile salmonellae fermented dulcitol. On the basis of this dulcitol fermentation test, these five 
dulcitol fermenter were grouped in to Salmonella gallinarum (OIE Manual, 1996). In this study, one nonmotile isolate did not ferment dulcitol. When one isolated organism produces acid and gas in dextrose, mannitol and xylose but did not ferment maltose (or fermentation occurred in later stage) and dulcitol, it is considered that the isolates is S. pullorum (OIE Manual, 1996). The dulcitol fermentation test is performed to differentiate nonmotile S. pullorum and S. gallinarum world wide (Robinson et al., 2000, Rahman, 2003).

Based on the motility, reaction in dulcitol and other biochemical tests, among 8 isolated samples, 5 (62.5\%) were considered to be $S$. gallinarum (fermented dulcitol and non motile), 1 (12.5\%) isolates were $S$. pullorum (did not ferment dulcitol but non motile) and rest 2 (25\%) (motile) were other Salmonella spp. (paratyphoid group). S. gallinarum was isolated from both ovary and liver, $S$. pullorum was isolated only from ovary and other salmonellae were isolated from liver and intestine (Table 3).

The occurrence of salmonellosis in present study was $11.42 \%$ which were relatively lower than the reports by other authors in Bangladesh (Talha et al., 2001; Saleque et al., 2003; Haider et al., 2004). This is probably due to the fact that other authors diagnosed the disease mostly based on the postmortem lesions. In this study the disease salmonellosis was confirmed by isolating the organisms from infected birds, necropsy findings and histopathological lesions.

Table 3. Occurrence of eight isolated Salmonella spp. in different organs

\begin{tabular}{|lllll|}
\hline Organ & S. gallinarum & S. pullorum & Other motile Salmonellae & Prevalence \\
\hline Liver $(\mathrm{n}=20)$ & 2 & - & 1 & $15 \%$ \\
Ovary $(\mathrm{n}=30)$ & 3 & 1 & - & $13.33 \%$ \\
Intestine $(\mathrm{n}=20)$ & - & - & 1 & $5 \%$ \\
\hline
\end{tabular}

$\mathrm{n}=$ Total samples cultured for isolation of Salmonellae

\section{Pathological study}

In pathological investigation, the results were found to be enlarged and congested liver with focal necrosis (Fig. 3), haemorrhagic, darker ovary with stalk formation (Fig. 4).

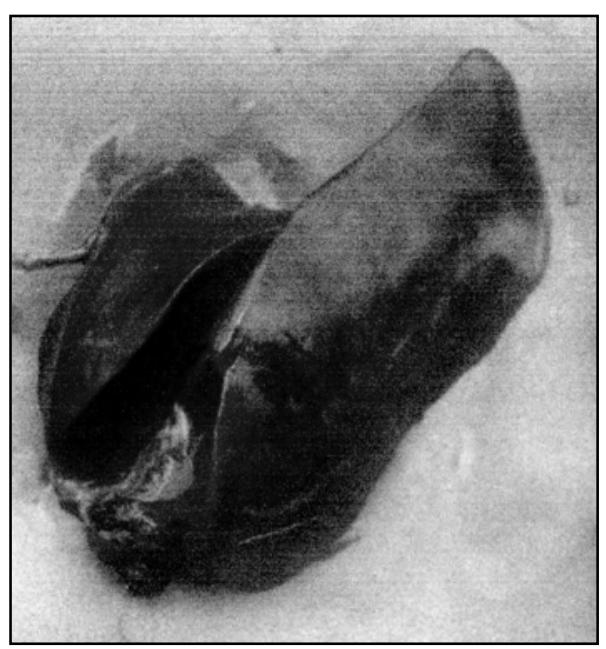

Fig. 3. Liver of Salmonella affected chicken showed swollen, shiny and bronze discoloration.

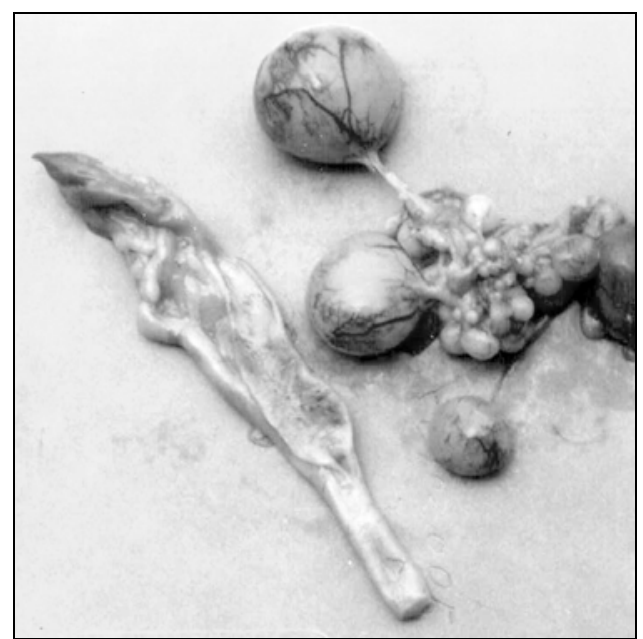

Fig. 4. Salmonella affected chicken showed old, raised hemorrhages in caecal tonsil (left), and hemorrhagic ovary with stalk formation (right). 
Microscopically, the liver showed focal degeneration, focal necrosis with infiltration of mononuclear cells. The intestinal mucosa exhibited congestion and hemorrhages with infiltration of mononuclear cells in the submucosa. These types of histological lesions are supported for Salmonella infection by different investigators (Talha et al., 2001; Habib-ur-Rahman et al., 2003; Haider et al., 2004).

In conclusion, the overall prevalence of salmonella infection is found $11.42 \%$ of which Fowl typhoid is $62.5 \%$, pullorum disease $12.5 \%$ and salmonellosis (paratyphoid infection) found $25 \%$. Liver and ovarian swab could be the choice for the isolation of salmonella infection. Hemorrhages in ovary with stalk formation and microscopically multi focal necrosis with infiltration of mononuclear cells in the liver could indicate the presence of salmonella infection.

\section{REFERENCES}

1. Brooks GF, Butel JS and Morse SA (2000). Jawetz, Melnick \& Adelberg's Medical Microbiology. $22^{\text {nd }}$ (international) edn., McGraw Hill, New Delhi, India. pp. 197-202.

2. Buxton A and Fraser G (1977). Animal Microbiology. Vol. 1. Blackwell Scientific Publications, Oxford, London, Edinburgh, Melbourne. pp. 103-115.

3. Cheesbrough M (1985). District Laboratory Practice in Tropical Countries, part-2. Cambridge low price edn., Cambridge University Press, UK. pp. 64-65.

4. Christensen JP, Olsen JE, Hansen HC and Bisgaard M (1993). Ribotypes of Salmonella enterica serovar Gallinarum biovars gallinarum and pullorum. Avian Pathology 22: 725-738.

5. Cown ST (1974). Cown and Steel's Manual for the Identification of Medical Bacteria. $2^{\text {nd }}$ edn., Cambridge University Press, Cambridge, UK.

6. Freeman BA (1995). Burrow's Text Book of Microbiology. $22^{\text {nd }}$ edn., W. B. Saunders Company, London, UK. pp. 372472.

7. Habib-ur-Rahman S, Sirzanin; Hamayun K, Saleem K, Nazir A and Bhatti WM. (2003). Incidence and gross pathology of Salmonellosis in chicken in Hyderabad. J. Asso. and Vet. Advances. 2: 581-584.

8. Haider MG, Hossain MG, Hossain MS, Chowdhury EH, Das PM and Hossain MM (2004). Isolation and characterization of Enterobacteria Associated with Health and Disease in Sonali Chickens. Banganladesh Journal of Veterinary Medicine 2 (1):15-21.

9. Hofstad MS, John BH, Calnek BW, Reid WN and Yoder Jr. HW (1992). Diseases of Poultry. $8^{\text {th }}$ edn., Panima Education Book Agency, New Delhi, Ind. pp.65-123.

10. Jones TC, Hunt RD and King NW (1997). Veterinary Pathology. $6^{\text {th }}$ edn., Williams and wilkins Co. Baltimore, USA.

11. Luna LG (1968). Manual of Histologic Staining Methods of the Armed Forces Institute of Pathology. $3^{\text {rd }}$ edn., McGraw Hill Book Co., New York, USA.

12. Merchant IA and Packer RA (1967). Veterinary Bacteriology and Virology. $7^{\text {th }}$ edn., The Iowa University Press, Ames, Iowa, USA. pp: 286-306.

13. OIE (Office International Des Epizooties) Manual (1996). 12 rue de Prony, 75017 Paris, France

14. Old DC (1990). Salmonella. In: Topley \& Wilson's Principles of Bacteriology, Virology and Immunity. $8^{\text {th }}$ edn., Parker NT and Duerden BI (eds). Vol. 2, Systematic Bacteriology. Edward Arnold. A division of Hodder \& Stoughton, London, UK. pp. 470-475.

15. Pomeroy BS and Nagaraja KV (1991). Fowl Typhiod. In: Diseases of Poultry, $9^{\text {th }}$ edn., BW Calnek, HJ Barnes, CW Beard, WM Reid and HW Yoder Jr. eds., Iowa State University Press, Ames, Iowa. pp. 87-99.

16. Rahman, M (2003). Growth of poultry industry in Bangladesh: Poverty alleviation and employment. In: Proceedings of $3^{\text {rd }}$ International Poultry Show and Seminar, from February 28 to March 2, 2003, held in Bangladesh China Friendship Conference Centre (BCFCC) at Sher-e-Bangla Nagar, Dhaka, Bangladesh. pp. 1-7.

17. Robinson H, Mdegela MGS, Yongolo U, Minga M and Johin E (2000). Molecular epidemiology of Salmonella gallinarum in chickens in Tanzania. Avian Pathology 29: 457-463.

18. Saleque MA, Rahman MH and Hossain MI (2003). Seasonal variation in the prevalence of poultry disease in Bangladesh. $9^{\text {th }}$ BSVER Annual Scientific Conference held at BAU, Mymensingh on 6-7 January, 2003 BSVER Publication 24: 23-24.

19. Shrama M and Katock RC (1996). Deadly outbreak in chicks owing to Salmonella typhimurium. Indian Journal of Poultry Science 31: 60-62.

20. Sujatha K, Dhanalakshmi K and Rao AS (2003). Isolation and characterisation of Salmonella gallinarum from chicken. Indian Veterinary Journal 80: 473-474.

21. Talha AFSM, Hossain MM, Chowdhury EH, Bari ASM, Islam MR and Das PM (2001). Poultry diseases occurring in Mymensingh district of Bangladesh. The Bangladesh Veterinarian 18: 20-23. 